Article

\title{
Crisis Management in Higher Education in the Time of Covid-19: The Case of Actor Training
}

\author{
Anna McNamara (D) \\ Guildford School of Acting, University of Surrey, Guildford GU2 7XH, UK; a.m.mcnamara@gsa.surrey.ac.uk
}

Citation: McNamara, A. Crisis Management in Higher Education in the Time of Covid-19: The Case of Actor Training. Educ. Sci. 2021, 11, 132. https://doi.org/10.3390/ educsci11030132

Academic Editor: Kelum Gamage

Received: 1 February 2021

Accepted: 16 March 2021

Published: 18 March 2021

Publisher's Note: MDPI stays neutral with regard to jurisdictional claims in published maps and institutional affiliations.

Copyright: (C) 2021 by the author. Licensee MDPI, Basel, Switzerland. This article is an open access article distributed under the terms and conditions of the Creative Commons Attribution (CC BY) license (https:// creativecommons.org/licenses/by/ $4.0 /)$.

\begin{abstract}
The impact of Covid-19 placed Higher Education leadership in a state of crisis management, where decision making had to be swift and impactful. This research draws on ethea of mindfulness, actor training techniques, referencing high-reliability organisations (HRO). Interviews conducted by the author with three leaders of actor training conservatoires in Higher Education institutions in Australia, the UK and the USA reflect on crisis management actions taken in response to the impact of Covid-19 on their sector, from which high-frequency words are identified and grouped thematically. Reflecting on these high-frequency words and the thematic grouping, a model of mindful leadership is proposed as a positive tool that may enable those in leadership to recognise and respond efficiently to wider structural frailties within Higher Education, with reference to the capacity of leaders to operate with increased mindfulness, enabling a more resilient organisation that unlocks the locus of control.
\end{abstract}

Keywords: high-reliability organisations; mindfulness; leadership; crisis management; resilience; frailty; burnout; Higher Education

\section{Introduction}

With the first cases reported in Wuhan, China, in December 2019, Covid-19 became a global issue rapidly, and was declared a pandemic, resulting in compulsory lockdowns across the world. These lockdowns forced Higher Education curricula online, creating great challenges for those involved in the delivery and receipt of learning and teaching [1]. According to Strielkowski and Wang, of "all the impacts brought about by the pandemic, one of the most profound ones is the impact on academia and higher education" [2] (p. 2), concluding that the issue of leadership in Higher Education takes on increased significance in the face of this challenge and therefore needs to be investigated further. To gain insight into the challenges faced by leadership in a time of crisis management brought about by the impact of Covid-19, interviews with colleagues holding senior positions within three major international actor training Higher Education conservatoires were carried out via video conference in September 2020. To attempt to gain a global perspective, colleagues were identified from the United States of America, the United Kingdom and Australia. Although it is understood that each institution and crisis is individual and nuanced, Covid-19 had such a large-scale globalised impact, the case study interviews drawn internationally from the actor training conservatoire sector could yield insights pertinent to leadership and crisis response in a range of settings across Higher Education.

The response to the Covid-19 pandemic in the United States of America saw over 1300 institutions from all 50 states transfer their delivery from face-to-face teaching to online methods, disrupting the delivery of the Spring semester of 2020 [3]. With the aim of reducing the spread of infection, the UK government introduced a requirement for people to stay at home, closing many businesses and venues and prohibiting all public gatherings of two of more people as of the 23rd of March 2020, with police granted powers to enforce these measures [4]. Subsequently, all UK Higher Education conservatoire delivery from this time until the end of the 2020 academic year was moved online. Australia has experienced 
a journey through the pandemic in 2020 that differed to the United States of America and the United Kingdom, but with social distancing measures in place and travel restrictions in force across states since March 2020, the impact of Covid-19, particularly on international students in Australian Higher Education, has been felt [5].

The impact of Covid-19 on Higher Education is likely to echo through academic cycles. This global pandemic has the potential for greater ramifications beyond the disruption of an academic year, placing economic strain and significant logistical constraints on education. The repercussions of the virus on the global performing arts industry further intensifies the pressure on actor training institutions at Higher Education to protect the students pedagogic experience. Maintaining the public-facing image and timely communications with academic communities becomes a dominant concern during crisis, and the effect of Covid-19 will necessitate a long road to recovery for the performing arts industries, including the actor training conservatoire sector. The perception of how successfully this crisis is managed can reflect the efficacy of the procedures enacted and magnify the frailties of processes and systems in place [6]. As the circumstances of a crisis are dynamic and multi-layered [7], the integrated communication with stakeholders is vital, as outcomes of actions taken do not take effect in isolation but interconnect due to the complex structures of organisations and communities [6], making defined tasks difficult to determine and measure in terms of success.

This paper aims to identify the relationship between procedural frailties exposed by crisis management [6] and the potential for community resilience enabled by mindful leadership against the backdrop of Covid-19. The central research enquiry poses whether a model of mindful leadership can be formed that may enable those in leadership to recognise and respond efficiently to wider structural frailties within Higher Education. The interviews conducted reveal the values held by these colleagues in leadership positions in the Higher Education conservatoire sector and indicate the common interpersonal and intrapersonal approaches they prioritised during the unplanned and unprecedented course of the first months of the 2020 Covid-19 crisis. Crises are "acute, public, arduous threats to an organization and its stakeholders" [7] (p.130). Resilience, or the capacity to cope with stressors, can be linked to job satisfaction, burnout and wellbeing [8], and these three contextual aspects of resilience, as identified by Ainsworth and Oldfield [8], are seen as processes with which the individual interacts within a broader social ecology; investment in the development of personal resilience is futile if not understood as part of a bigger environmental picture.

\section{Mindfulness, Resilience and High-Reliability Organisations (HROs)}

Mindfulness has increasingly become linked with notions of resilience within a prolonged environment of uncertainty [9] in professional settings [10], and the understanding of resilience as something which sits at the intersection of the individual within their social context $[8,10,11]$ informs this paper's perspective of resilience. Drawing on concepts of academic burnout, with burnout defined as a "product of stress" [12] (p. 400), characterised by exhaustion and a sense of isolation, and mindful leadership [6], it is proposed that effective resilience strategies, as understood and experienced by students and teachers, are influenced directly by the mindful approach, or lack thereof, put into practice by senior academic management [13].

Webster and Rivers [10] highlight the growing discourse surrounding hegemonic concepts of resilience in Higher Education and beyond, firmly rejecting what the authors articulate as the growing popularisation of the notion of the tough and capable autonomous individual as a toxic threat to a developed nuanced appreciation of a collective understanding of self. Webster and Rivers place perspectives of resilience within a neoliberal context, where meritocracy trumps collaborative-social growth, and commonly held superficial perceptions of resilience serve to exacerbate the hierarchical distances between those in power and those upon who the power is exacted. Thus, the authors propose that such popularist notions of resilience diminish the positive perceptions of the dynamic agile col- 
lective and compound pressure upon individuals to perform under unreasonable pressures and structures. Zembylas [11] picks up on and draws directly upon this critical perspective of resilience and advocates for a "political framing of subjectivities in education" [11] that contextualises how the discursive trends surrounding resilience impact and intensify power dynamics and (im)balances within Higher Education communities. From this viewpoint, it is offered that it is the role of the mindful leader to unlock the locus of control [14] to empower the community to come toward a collaborative and shared resilient working practice. Levey and Levey [6] identify two approaches to mindfulness and resilience in the workplace. As with Zembylas, and also Webster and Rivers, Levey and Levey emphasise the value of centring views of wellbeing on a collectively developed appreciation of a sustainable life skill. This shared ability to be cooperatively present will come to be of particular benefit, the authors argue, in time of volatility and uncertainty [6]. By working together equitably, the collective can make advantageous gain on opportunities [15], as the "deficiencies" [16] (p.2) in the operation and delivery of Higher Education become exposed and enable a shared contextual understanding of resilience [12], seeking to navigate away from exposure to the risks of burnout [17].

To understand how pedagogic health and resilience can be optimised in the face of crisis, protecting teachers from burnout due to unrealistic expectations and demands [12,14], lessons can be drawn from high-reliability organisations (HRO). HROs' exposure to stressors, Pillay, Enya and Boateng [18] describe, is an inescapable, defining part of their routine and culture and yet the $\mathrm{HRO}$ can operate through uncertainty and great complexity in the face of potentially catastrophic consequences to error. HROs function in scenarios where risk or exposure to risk are a major factor in their regular operations. To reduce the capacity for fault or human error, HROs invest in collaborative processes that enable reflection and development. Mellor, Wilday, Lunt and Holroyd [19] assert that HROs establish a mindful environment that enables them to deal with the unpredictable nature of their contexts, cultivating a way of operating that continually reflects, refines and refreshes practices and processes. As seen in Mellor, Wilday, Lunt and Holroyd's model of HROs, mindful leaders recognise that they cannot solve crises of both a relational and an operational nature simultaneously on their own, as their time and ability to work to capacity in a multi-faceted way is diminished [10], so a collegiate approach that empowers 'bottom up' communication [6], in line with the "reporting, just, flexible culture" [19] (p.1) is required. Such an approach, Fear asserts, allows space for an equitable approach to reflection from all stakeholders, giving respite from top-down task driven directives to those responding to leadership, enabling a more equitable "process for proactive implementation and improvement." [20] (p. 3).

Early in the development of the global pandemic, Fernandez and Shaw articulated a vision for academic leadership in the face of crisis [21], emphasising the value of transformative, rather than transactional leaders [22] who can connect to create a team that communicates clearly and responds to crises with flexibility. Although Gelles, Lord, Hoople, Chen and Mejia [23] identify a landscape of literature that reflects upon the impact of historic crises upon Higher Education including natural disasters and the H1N1 influenza virus (commonly referred to as swine flu), Fernandez and Shaw, acknowledging trends in literature that invest in researching the impact of leadership upon the commercial business sectors, point to a lack of research in academic leadership in times of crisis [22]. The following method and reflections seek to contribute to this landscape, integrating the consideration and framing of resilience and wellbeing as offered in the literature review with leadership actions in Higher Education settings, through the lens of the actor training conservatoire.

\section{Methodology}

3.1. Participants

The interviewees and the respective institutions were: 
- Scott Edmiston, Dean of Theater, Boston Conservatory at Berklee, United States of America.

- Professor Sean McNamara, Head of the Guildford School of Acting, University of Surrey, United Kingdom, Chair of the Federation of Drama Schools, United Kingdom. - Professor David Shirley, Executive Director, Western Australia Academy of Performing Arts, Edith Cowan University, Australia.

Informed consent was obtained from the participants at the beginning of each interview, with full disclosure given by the interviewing author as to the purpose of this study and intended subsequent publication. All were made aware of their right to withdraw from the process at any time up to publication and that engagement with the process was on a voluntary basis. Each interviewee granted full permission for their names and institutions to be disclosed.

As only three interviews were to be conducted, the purpose of the approach was to give insight into processes undertaken by actor training conservatoire leaders in Higher Education in the face of the unfolding and ongoing impact of the global coronavirus pandemic in 2020. These results are not to be generalised to all Higher Education settings and departments, but the understanding gained from these perspectives may be applicable and helpful across different academic sectors.

\subsection{Participant Contexts}

All participants were known to the author prior to the interviews being conducted. In 2017, the Federation of Drama Schools (FDS) was formed to provide a network of critical friends and alliances amongst UK based actor training conservatoires. As of the beginning of 2021, there is not yet an official global network for actor training conservatoires through which practitioners and educators can interact and reflect upon daily practice and meaning making [14] in a way that will carry influence or formally steady the terrain of change. However, informal relationships exist and although the daily interaction and accidental exchange has been somewhat lost on an in-person local level for schools and departments during the Covid-19 lockdown, there has been an opportunity to liaise across institutions and continents with colleagues globally to bring understanding to the state of the worldwide sector. Although these liaisons and affiliations may have arisen from a subconscious desire for affirmation from these relationships [14], the positive benefits of seeking out critical friends in the context of this research is executed in the hope that findings may be of benefit to a wider Higher Education discourse beyond the actor training sphere. From this viewpoint, the author, as an academic pedagogic leader in conservatoire actor training in UK Higher Education, extended invitations to three leaders of internationally respected actor training conservatoires that operate within Higher Education settings to participate in a scaffolded interview.

With a history spanning more than a century, The Boston Conservatory at Berklee offers undergraduate and postgraduate degrees in music, dance, and theatre to approximately 750 students each year. The Guildford School of Acting was founded in 1935 and provides undergraduate and postgraduate degrees in acting, actor-musicianship, dance, musical theatre, theatre production and theatre to over 700 students annually. The Western Australia Academy of Performing Arts has been providing undergraduate and postgraduate training since 1980, now offering programmes in aboriginal performance, acting, arts management, dance, music, music theatre, performing arts and production and design. From March 2020, the provision of all learning and teaching activities at both the Boston Conservatory and the Guildford School of Acting moved to remote online delivery.

\subsection{Procedures Followed}

The interviews each shared a framework centring on four key questions, detailed below in Table 1. The intention behind this loose structure was to enable the interviewee to develop their thoughts and expand upon their reflections without interruption or influence. Interviews were conducted one by one via video conferencing software Zoom in September 
2020, with the author serving as interviewer. The video conferencing transcript function was utilised to create a downloadable transcript, which then only required minor editing for accuracy post interview, due to software misinterpretation of occasional words.

Table 1. A summary of the interviews detailing high-frequency words in response to questions.

\begin{tabular}{c} 
Prompt Question \\
\hline \\
1. What were the challenges that you feel you faced as \\
a leader in Higher Education of a conservatoire?
\end{tabular}

2. What do you perceive were your roles or responsibilities in the face of that challenge?
3. What do you think was the impact of the quality of your actions?
4. How did you deal with the personal cost and challenge?

\begin{tabular}{|c|c|}
\hline Words Used Most Frequently & Frequency Utilised \\
\hline Students & 8 \\
\hline Technology & 7 \\
\hline Information & 6 \\
\hline Delivery & 5 \\
\hline Environment & 5 \\
\hline Leading & 5 \\
\hline Reassure & 5 \\
\hline Anxious & 4 \\
\hline Communicate & 4 \\
\hline Impact & 4 \\
\hline Training & 4 \\
\hline Decisions & 3 \\
\hline Understand & 3 \\
\hline Unknown & 3 \\
\hline Certainty & 8 \\
\hline Feeling & 7 \\
\hline Colleagues/Staff & 6 \\
\hline Humans & 6 \\
\hline Experience & 5 \\
\hline Opportunity & 5 \\
\hline Process & 5 \\
\hline Communication & 4 \\
\hline Daily & 4 \\
\hline Presence & 4 \\
\hline Provide & 4 \\
\hline Available & 3 \\
\hline Care & 3 \\
\hline Expectation & 3 \\
\hline Guidance & 3 \\
\hline Problem solving & 3 \\
\hline Reassurance & 3 \\
\hline Represent & 3 \\
\hline Responsible & 3 \\
\hline Resources & 3 \\
\hline Training & 3 \\
\hline Welfare & 3 \\
\hline Tone & 5 \\
\hline Acknowledge & 4 \\
\hline Reassure & 4 \\
\hline Decision & 3 \\
\hline Detail & 3 \\
\hline Effective & 3 \\
\hline Focus & 3 \\
\hline Understood & 3 \\
\hline Work & 16 \\
\hline Home & 8 \\
\hline Everyday & 5 \\
\hline Opportunity & 5 \\
\hline Absence & 4 \\
\hline Family & 4 \\
\hline Feeling & 4 \\
\hline Recognise & 4 \\
\hline Strong & 4 \\
\hline Altered & 3 \\
\hline Capacity & 3 \\
\hline Children & 3 \\
\hline Effective & 3 \\
\hline Focus & 3 \\
\hline Separate & 3 \\
\hline Unhealthy & 3 \\
\hline
\end{tabular}

Following the interviews, each transcript was colour coded, one colour for each interviewee, and directly transferred to a combined spreadsheet where the frequency of 
words was captured. Once high-frequency connectives were removed from the spreadsheet, the remaining high-frequency words were captured in table form. The next step of this part of the data-filtering process was to eliminate any high-frequency words that were not spoken by all three interviewees, leaving only the shared common words in table form, listed by most mentioned to least (see Table 1, below).

Finally, following a visual analysis of the words contained in Table 1, the words were sorted into three groups under the emerging headings Culture and Values, Communication and Collegiality. These three groupings were each collated into a further table (see Table 2, below) with the data in each grouping sorted by frequency. A group weighting was assigned to the data under each of the three headings, achieved by dividing the total frequency of combined mentions of all words across the group by the number of different words found within the group.

Table 2. A summary of high-frequency words within the interviews, grouped by theme.

\begin{tabular}{|c|c|c|}
\hline Group Heading & Words Used Most Frequently & Frequency Utilised \\
\hline \multirow{23}{*}{ Culture and Values } & Work & 16 \\
\hline & Feeling & 11 \\
\hline & Opportunity & 10 \\
\hline & Certainty & 8 \\
\hline & Home & 8 \\
\hline & Students & 8 \\
\hline & Focus & 6 \\
\hline & Environment & 5 \\
\hline & Everyday & 5 \\
\hline & Experience & 5 \\
\hline & Process & 5 \\
\hline & Anxious & 4 \\
\hline & Family & 4 \\
\hline & Impact & 4 \\
\hline & Strong & 4 \\
\hline & Altered & 3 \\
\hline & Capacity & 3 \\
\hline & Children & 3 \\
\hline & Problem solving & 3 \\
\hline & Responsible & 3 \\
\hline & Unhealthy & 3 \\
\hline & Unknown & 3 \\
\hline & Welfare & 3 \\
\hline \multirow{17}{*}{ Communication } & Reassurance & 12 \\
\hline & Communicate & 8 \\
\hline & Technology & 7 \\
\hline & Decision & 6 \\
\hline & Effective & 6 \\
\hline & Information & 6 \\
\hline & Understand & 6 \\
\hline & Delivery & 5 \\
\hline & Leading & 5 \\
\hline & Tone & 5 \\
\hline & Absence & 4 \\
\hline & Daily & 4 \\
\hline & Recognise & 4 \\
\hline & Detail & 3 \\
\hline & Expectation & 3 \\
\hline & Represent & 3 \\
\hline & Separate & 3 \\
\hline \multirow{10}{*}{ Collegiality } & Training & 7 \\
\hline & Colleagues/Staff & 6 \\
\hline & Humans & 6 \\
\hline & Acknowledge & 4 \\
\hline & Presence & 4 \\
\hline & Provide & 4 \\
\hline & Available & 3 \\
\hline & Care & 3 \\
\hline & Guidance & 3 \\
\hline & Resources & 3 \\
\hline
\end{tabular}




\section{Results}

Key themes that arose through each of the interviews are detailed below in Table 1, recording the frequency of repeated key words used by the three interviewees across all three discussions, along with the prompt questions proposed by the author/interviewer. These are listed below with the words that occurred most first.

A visual analysis of this data clearly illustrates the shared vocabulary utilised across each of three interviewees, as all repeated words that were not spoken by all interviewees have been eliminated. However, it was evident that a further sort of the data was necessary to achieve a meaningful analysis of the data. The process of combining the data into one list enabled a visual sorting, yielding three distinct groupings of the high-frequency words under the headings Culture and Values, Communication and Collegiality (Table 2, below).

The emerging groupings suggested three core themes within the discussions of leadership arising from the four questions used to scaffold the three interviews. To gain a sense of the balance of the groupings through the data yield, a group weighting was assigned to the data under each of the three headings, achieved by dividing the total frequency of combined mentions of all words across the group by number of different words found within the group (see Table 3, below).

Table 3. Balance of high-frequency words across each themed group.

\begin{tabular}{cccc}
\hline Group Heading & Number of Words in the Groups & Total Frequency of all Words across the Group & Weighting \\
\hline Culture and Values & 23 & 127 & 5.5 \\
\hline Communication & 17 & 90 & 5.3 \\
\hline Collegiality & 10 & 43 & 4.3 \\
\hline
\end{tabular}

Culture and Values had a greater weighting than the words grouped under Communication, which in turn was greater than the weighting of the words under the heading Collegiality. As this data set is collated from a small-scale study consisting of just three interviews, and the purpose of the approach within this research is to give insight into processes undertaken by Higher Education conservatoire leaders in 2020, it is not appropriate to attempt to draw definitive statistical conclusions from this. These results are not to be generalised to all Higher Education settings and departments, but the understanding gained from these perspectives may be applicable across different academic sectors and serve to inform the discussion below.

\section{Discussion}

Mellor, Wilday, Lunt and Holroyd [19] called for the qualities of mindful leadership to be defined in more applied terms, so that a practical, real-world development may be understood. In direct response to the interview findings and from the literature reviewed, Figure 1, below, brings together a new model of mindful leadership for a resilient Higher Education organisation utilising the three group headings identified in Table 2 above, drawn from the high-frequency words within the three interviews. The model presented here synthesises extant qualities of mindfulness and of leadership as defined by the highfrequency words and phrases utilised across the three interviews, although the model may adapt and synergise keywords and labels, and further develops the findings from the literature reviewed, including 'Qualities of Mindful Leadership', as defined by Wells [13] (p. 17), as well as integrating mindful leadership's commitment to collaborative community resilience $[15,16]$. This new model for mindful leadership (Figure 1) therefore establishes the essential communication of leaders in times of crisis as a combined enterprise $[6,24]$ that demonstrates understanding and the embracing of a shared culture [7] and value system [20]. 


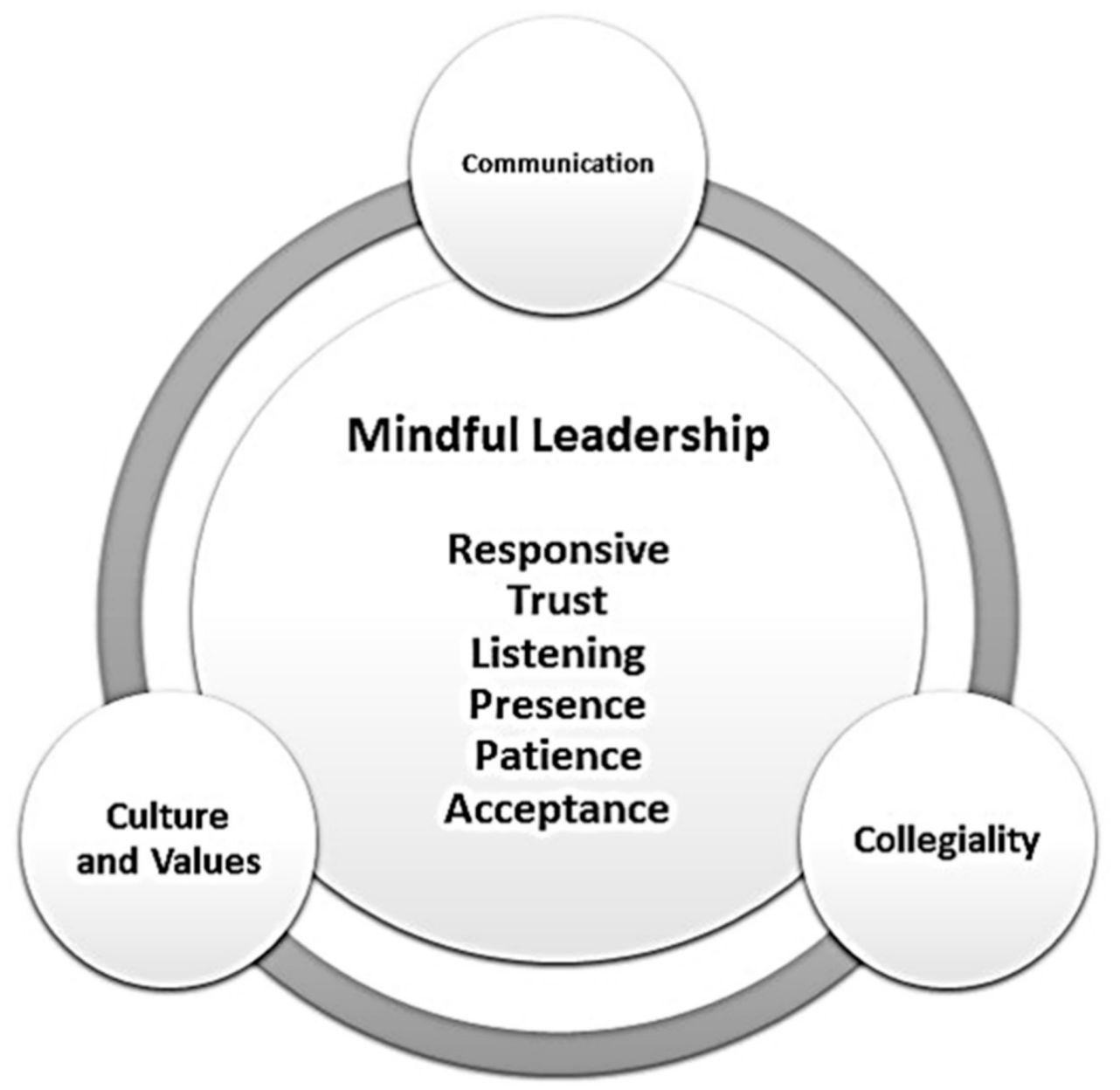

Figure 1. A model of mindful leadership arising from this study, drawn by the author.

Lessons learned from HROs, as exemplified in the literature review, demonstrate that crisis management disrupts the healthy suppleness and agility of an organisation, and therefore a re-connection to a balanced awareness of the wider perspectives beyond the immediate crisis is essential for an organisation's healing and ability to move forward in a unified manner [10]. Authenticity and awareness are key to process and as with the example of HROs, this must be an integral step in the process of crisis management [24]. As Harvard Professor of Psychology and proponent of mindfulness/mindlessness Dr. Helen Langer articulates: "When we are mindless we hold our perspective still allowing us to confuse the stability of our mindsets with the stability of the underlying phenomena. Hold still if you want but its changing nonetheless." [15]. Drawing from these perspectives, the model below proposes that the mindful leader is collegiate, interacting dynamically with co-workers, students, and other key stakeholders, knowing that collaboration and cooperation reduces risk and enhances capability for recovery [25]. The mindful leader shares core values and visions [7] with colleagues and understands a common cultural language of trust and presence with the wider institution [9]. They are respectful, clear, and equitable communicators with stakeholders, both internally and externally [7], who engage actively with listening and who respond with compassion [13]. They engender professional environments built on a foundation of trust; trust in processes as well as in people, understanding that mindful leadership is "a way of being as opposed to a way of doing" [13] (p. 1). Patience and acceptance are key features of the mindful leader, responding without judgement [13].

For Higher Education conservatoires to envisage progressive training post Covid-19, this model proposes that leadership needs to enable an environment that fosters a sense of 
collegiality and enables effective communication within a shared culture and value system. The model in Figure 1, drawn from literature as well as the three interviews, sits in contrast to the model of mindless leadership presented below in Figure 2.

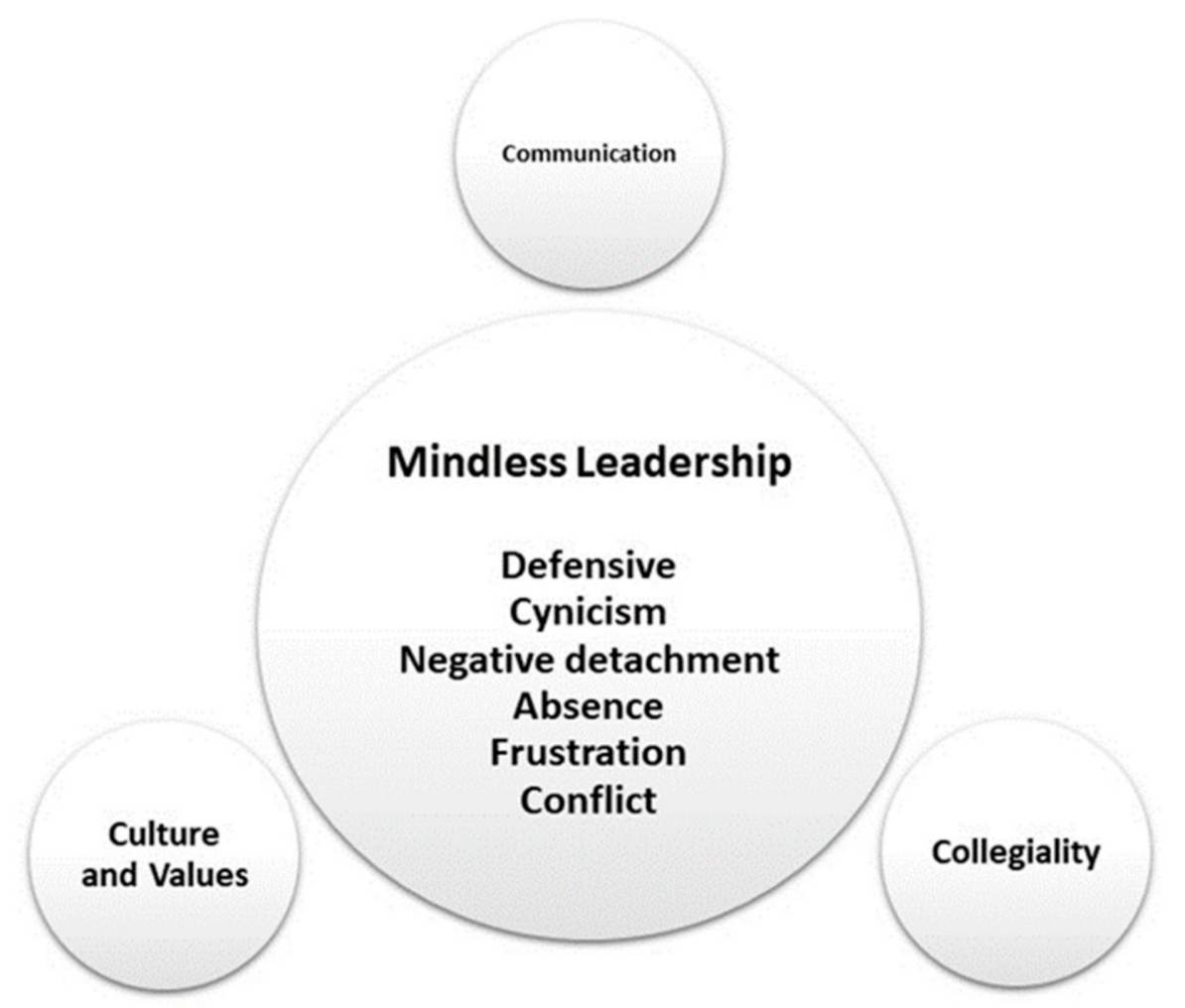

Figure 2. A model of mindless leadership arising from this study, drawn by the author.

The model of mindless leadership (Figure 2) demonstrates the negative effect of leadership that suffers from poor communication and an isolated disconnect from the institution's culture and values, increasing the capacity for error and misjudgement [9], the impact of which can result in a high risk of burnout for the Higher Education organisation where overwhelming stress accrues [9]. This sense of division means the mindless leader is unable to communicate effectively [6] and does not embody a collegial approach to daily practices, working in isolation [7]. The language used to describe and define the mindless leader is opposite to that found in the descriptors of the mindful leader. The mindless leader displays traits such as being defensive and having an air of cynicism in their dealing with people, processes, and tasks, unable to act with compassion or to manage the emotions of stakeholders [7]. Operating with a negative detachment from the work, from colleagues, from students and/or from their environments, they are absent and frequently demonstrate frustration at given scenarios or individuals, perhaps as a result of the crisis exciting strong emotions, or a reliance on biased decision making [7]. There is conflict for the mindless leader, with themselves, with others, with their environ, and/or the culture and values of the institution that results in volatility and ambiguity [9]. This sits at odds with the invested thoughtfulness and innovation required to effectively survive crisis scenarios [7], leading to increased risk of error and poor judgement when "individual attention is scattered, distracted, short lived, and dominated by abstractions" [19] (p. 3).

Kinchin [13] uses the analogy of invisible pathologies to discuss our navigation of difficult topics subjects and issues; if we ignore the pathologies, because they are invisible, they can remain unseen, but they will not go away. As with the practices of HROs, by actively engaging with the process of seeking a cure or resolution, we can learn to understand the problem better and we acquire knowledge of how to proceed in a way that will lessen the risk of harm. So too in Higher Education conservatoire settings, 
when we become preoccupied with a task or output, we ignore the lessons that can be learned from the examples of actively reflective HROs and from collaborative models of community resilience as outlined in the literature reviewed, becoming divorced from the vitally important job of genuinely examining and engaging with the processes and systems that connect tasks and outcomes [20], as articulated in the models drawn from the interviews conducted. Here lies the connecting frailty, as Cartier and Taylor succinctly articulate; "resilience is a process, rather than an outcome" [6] (p. 2).

This study has several limitations. Specifically, and most importantly is the knowledge that only three leaders were included in the interview process. By our absorption with crisis management, coping and getting by day to day, there is a possibility that we have shut out the wider perspective of systemic issues of frailty in Higher Education. When we emerge from crisis management, these issues of frailty will still be there if no one has undertaken the pursuit of reflection and examination. To determine a wider picture of the challenges and values held by conservatoire leadership in Higher Education settings across the sector as a whole, further enquiry and research is recommended.

\section{Conclusions}

Despite the small-scale nature of the research conducted, in response to the central research enquiry of whether a model of mindful leadership can be proposed that may enable those in leadership to recognise and respond efficiently to wider structural frailties within Higher Education, two illustrative models of leadership in conservatoire Higher Education have emerged. These were formed from the interviews conducted, alongside the literature reviewed. These models of mindful and mindless leadership seek to highlight the importance of connectivity between leadership, context, and community, elevating the value of the links and lines of communication that bind. Although further testing of the leadership models is recommended through larger-scale research, these two models aspire to demonstrate that it is the relationships and the processes, rather than the actions or the concerns, that hold the solutions to the problems to be addressed.

To enable resilient communities, we must form alliances of critical friends, learning from the example of the HRO by engaging in a frank and open reflective discourse to recognise and expose shared frailties within structural processes and systems of operation and practice, in the knowledge that naming frailty is not equal to weakness, but rather acts to stimulate communal resilience. By doing so, academia may well stand to benefit from the pandemic [2]. There is a beauty and a craft in the fragile and the delicate, and there is strength in the resilience required to withstand tremendous attention-diverting pressures. In moving beyond focusing on the stressors of the immediate scenario, communities in Higher Education may be able to respond and progress in the face of tensions. There is power in knowing and naming frailties; this is strength, not vulnerability.

Funding: This research received no external funding.

Institutional Review Board Statement: The study was conducted according to the guidelines of the Declaration of Helsinki, and approved by the Institutional Ethics Committee of the University of Surrey (protocol code 640816-640807-72017777 8/2/2021).

Informed Consent Statement: Informed consent was obtained from all subjects involved in the study.

Data Availability Statement: The data presented in this study are available on request from the corresponding author. The data are not publicly available due to requests from the interviewees.

Conflicts of Interest: The author declares no conflict of interest.

\section{References}

1. Almazova, N.; Krylova, E.; Rubtsova, A.; Odinokaya, M. Challenges and Opportunities for Russian Higher Education amid Covid-19: Teachers' Perspectives. Educ. Sci. 2020, 10, 368. [CrossRef]

2. Strielkowski, W.; Wang, J. An Introduction: COVID-19 Pandemic and Academic Leadership. Adv. Soc. Sci. Educ. Humanit. Res. 2020, 441, 1-4. 
3. Smalley, A. Higher Education Responses to Coronavirus (Covid-19). Available online: https://www.ncsl.org/research/ education/higher-education-responses-to-coronavirus-covid-19.aspx (accessed on 30 January 2021).

4. Full Guidance on Staying at Home and Away from Others 2020. Available online: https://www.gov.uk/government/ publications / full-guidance-on-staying-at-home-and-away-from-others (accessed on 27 October 2020).

5. Bairagi, R. Impacts of COVID-19 on Australian Higher Education Export-A Discussion. Econ. Sustain. Dev. 2020, 11, 23-28.

6. Cartier, E.A.; Taylor, L.L. Living in a wildfire: The relationship between crisis management and community resilience in a tourism-based destination. Tour. Manag. Perspect. 2020, 34, 100635. [CrossRef]

7. König, A.; Graf-Vlachy, L.; Bundy, J.; Little, L.M. A Blessing and a Curse: How CEOs' Trait Empathy Affects Their Management of Organizational Crises. Acad. Manag. Rev. 2020, 45, 130-153. [CrossRef]

8. Ainsworth, S.; Oldfield, J. Quantifying teacher resilience: Context matters. Teach. Teach. Educ. 2019, 82, 117-128. [CrossRef]

9. Levey, J.; Levey, M. Mindful Leadership for Personal and Organisational Resilience. Clin. Radiol. 2019, 74, 739-745. [CrossRef] [PubMed]

10. Webster, D.; Rivers, N. Resisting Resilience: Disrupting Discourses of Self-Efficacy. Pedagog. Cult. Soc. 2019, 27, 523-535. [CrossRef]

11. Zembylas, M. Against the Psychologization of Resilience: Towards an Onto-Political Theorization of the Concept and Its Implications for Higher Education. Stud. High. Educ. 2020, 1-12. [CrossRef]

12. Howard, S.; Johnson, B. Resilient teachers: Resisting stress and burnout. Soc. Psychol. Educ. 2004, 7, 399-420. [CrossRef]

13. Wells, C.M. Conceptualizing Mindful Leadership in Schools: How the Practice of Mindfulness Informs the Practice of Leading. Educ. Leadersh. Rev. Dr. Res. 2015, 2, 1-23.

14. Kinchin, I. Mapping the Terrain of Pedagogic Frailty. Pedagogic Frailty and Resilience in the University, 1st ed.; Kinchin, I., Winstone, N.E., Eds.; Sense Publishers: Rotterdam, The Netherlands, 2017; pp. 1-16.

15. Harvard Business Review. Available online: https://hbr.org/2010/04/leaders-time-to-wake-up (accessed on 20 August 2020).

16. Watermeyer, R.; Crick, T.; Knight, C.; Goodall, J. COVID-19 and Digital Disruption in UK Universities: Afflictions and affordances of emergency online migration. High. Educ. 2020, 81, 623-641. [CrossRef] [PubMed]

17. Maslach, C.; Leiter, M.P. Understanding the Burnout Experience: Recent Research and Its Implications for Psychiatry. World Psychiatry 2016, 15, 103-111. [CrossRef] [PubMed]

18. Pillay, M.; Enya, A.; Boateng, E. High Reliability Organisations and Collective Mindfulness for Improving Healthcare Safety Management: A Scoping Review Protocol of Factors, Measures and Instruments. Int. J. Occup. Environ. Saf. 2019, 3, 8-13. [CrossRef]

19. Mellor, N.; Wilday, J.; Lunt, J.; Holroyd, J. High Reliability Organisations and Mindful Leadership; Hazards 25 Symposium Series No. 160; 2015; pp. 1-5. Available online: https:/ /www.icheme.org/media/8499/xxv-paper-32.pdf (accessed on 27 October 2020).

20. Fear, W.J. High Reliability Organisations: A Model for School Effectiveness? Available online: https://www.dropbox.com/sh/z3 8btgp0cvcn7bl/_6AIh0CeHw (accessed on 27 October 2020).

21. Fernandez, A.; Shaw, G. Academic Leadership in a Time of Crisis: The Coronavirus and COVID-19. Leadersh. Stud. 2020, 14, 39-45. [CrossRef]

22. Fernandez, A.; Shaw, G. Leadership in Higher Education in an Era of New Adaptive Challenges. Available online: https: / / library.iated.org/view / FERNANDEZ2020LEA (accessed on 30 January 2021).

23. Gelles, L.; Lord, S.; Hoople, G.; Chen, D.; Mejia, J. Compassionate flexibility and self-discipline: Student adaptation to emergency remote teaching in an integrated engineering energy course during COVID-19. Educ. Sci. 2020, 10, 304. [CrossRef]

24. Trachsler, T.; Jong, W. Crisis Management in Times of COVID-19: Game, Set or Match? J. Contingencies Crisis Manag. 2020, 28, 485-486. [CrossRef]

25. Sawyerr, E. Harrison, Developing Resilient Supply Chains: Lessons from High Reliability Organisations. Supply Chain Manag. 2020, 25, 77-100. [CrossRef] 